\title{
Os Enfoques Universalista e Regionalista no Direito Internacional.
}

\author{
Pela Justiça Social Internacional
}

\section{Haroldo Valladão}

Catedrático de Direito Internacional Privado das Universidades Federal e Católica do Rio de Janeiro.

\begin{abstract}
SUMÁrro 1. Objeto do trabalho: colocação em evidência, principios e normas do D.I., sob os signos do universalismo $e$ do regionalismo. 2 . O moderno D.I. positivo nasce, Séculos $\mathrm{XV} e \mathrm{XVI} e$ se consolida, Séculos XVח e seguintes, regionalista, individualista, na Europa. 3. Teólogos e moralistas protestam e apresentam o verdadeiro D.I., sob o signo universalista. 4. A precária posição dos juristas. 5. O D.I. europeu, regionalista, individualista, fragmentário, aristocrático. 6. Sua exacerbação no Século xIx, dominio da Africa e Asia. 7. O D.I. americano, regional, mas com espirito universalista, comunitário, orgânico, democrático. 8 . O primeiro encontro entre o D.I. europeu e o americano: Haia, 190\%. 9. O reconhecimento europeu do D.I. americano. 10. Síntese universalista, marcha da democratização: da igualdade para a solidariedade. 11. A Sociedade das Nações e a continentalização do panamericanismo. 12. As Nações Unidas e sua democratização com a abolição do colonialismo. 13. A OEA $e$ o pan-americanismo econômico e social. 14. Universalizaçāo da sociedade econômica e social: os EUA e as Nações Unidas. 15. Desenvolvimento $e$ integração como deveres internacionais. 16 . Os penúltimos progressos. 17. Marcha para a Reforma e Atualização da Justiça Internacional. 18. Internacionalização $e$ universalismo.
\end{abstract}

1. Sobre os enfoques universalista e regionalista no direito internacional, cabe-nos pôr em evidência os pontos essenciais ou de convergência (e o faremos quanto a alguns, principais), verificados nos princípios e normas do direito internacional, sob os signos do universalismo e do regionalismo.

Ficamos, objetivamente, no tema proposto, excluindo matéria, universalismo e regionalismo nas organizações internacionais. 
Veremos que o direito internacional, positivo, hist6rico, nasce e se desenvolve regionalista, mas evoluindo sempre, doutrinária e idealisticamente, para reencontro e realizações universalistas.

2. O moderno direito internacional 1, "jus intergentes", direito entre os Estados, nasceu nos Séculos XV e XVI, contemporâneo do período das grandes descobertas e descobrimentos geográficos e vai se consolidar nos Séculos XVII e seguintes, com a marca rigorosamente individualista, de uma nova e larga sociedade internacional, pluricontinental, oceânica, mas desierarquizada, rompida a unidade cristã, intelectual, espiritual e política da restrita sociedade de povos pequenos e vizinhos do mundo mediterrâneo medieval.

Constituíram-se então os grandes e poderosos Estados, nacionais, centralizados, de caráter patrimonial, num absolutismo que a Reforma ajudava, desprendendo-os de um único e Supremo Poder Espiritual, e que os famosos legistas reais justificavam invocando, por analogia, rigorosos princípios do direito romano, na corrente intelectual da Renascença. Aparece e desenvolve-se a idéia de soberania do Estado que se estende, com a mesma agressividade, na ordem interna, pela sujeição total de indivíduos e regiões, e na ordem internacional com a independência absoluta do Estado e sua desenfreada expansão, em particular nos mares e terras recém-conhecidos, à procura de terras e povos para conquistá-los, isto é, para ocupar, subjugar, explorar e escravizar. O espírito era de lucro desenfreado, verdadeiro animus furandi, à cata de especiarias, de ouro, de prata...

E o resultado foi a aquisição pelas nações descobridoras e conquistadoras, Espanha, Portugal, e a seguir, Inglaterra, Holanda e França, de grandes territórios, de verdadeiros continentes, com a escravização e, não raro, o extermínio dos povos que os ocupavam.

o regime era do individualismo absoluto na ordem internacional: a caça desenfreada à terra e ao "bárbaro"; o domínio ao conquistador, ao "captor", ao primeiro descobridor ou aos primeiros ocupantes, ao "adquirente" de certa porção de terras aos selvagens. E domínio ilimitado, que se estenderia amplamente pelo princípio da continuidade, a partir do ponto da costa ocupado.

1. Vd. H. Valladão, Democratização e Socialização do Direito Internacional, Rio, 1961, p. 16 e ss. e em francês, Democratization et Socialization du Droit International, Paris, Sirey, 1962, pages 16 et ss.; em castelhano, Colégio do México, México, 1963. 
Eis, aí, o pecado original do moderno direito internacional que tinha a sua vivência cultural nas obras, tão lidas pelos monarcas, de governo fora da moral, de NICOLAU MAQUIAVEL, 1469-1527, em especial no Príncipe e nos Discursos sobre Tito Lívio", pois ele expõe, defende e estimula e, afinal, glorifica a conquista e a ocupação pelas armas e de Bodin, La Republica, onde consolidava o absolutismo com o conceito básico do "poder soberano", "puissance perpetuelle et absolue de la Republique".

Mas é mister um novo direito a regular as relações desses ambiciosos Estados entre si e no trato com as novas gentes, nos problemas jurídicos da navegação marítima de longo curso, da propriedade, do uso e dos limites dos recém-descobertos mares e terras, da submissão dos gentios...

A intervenção dos Papas para os Estados Católicos, Espanha e P.ortugal, inclusive a divisão do globo terrestre entre eles, Bula Inter Coetera, não apaziguou os ânimos.

Afastado, assim, o poder da Santa Sé, mesmo entre os Estados católicos, as relações internacionais oscilando entre guerras, negociações diplomáticas e acordos e tratados, assumem natureza puramente voluntarista, norteadas pelos interesses políticos, baseando-se nos princípios individualistas romanos do imperium, do dominium, da guerra, do contrato, da compra e venda, da doação, da sucessão .

$\mathrm{E}$ vai se formando nessa base político-individualista romanista um conjunto de regras e de praxes, de tratados e de costumes, aparecendo, assim, um uso que tanto influenciará o moderno direito internacional. Proclama-se a soberania e a independência e até a igualdade dos Estados poderosos, pois admitiam-se a conquista e a escravidão como resultados das guerras, e, na ausência de hierarquia na sociedade internacional, cria-se e organiza-se o sistema, puramente político, do equilíbrio europeu.

3. De nada valeram para os Reis e os Imperadores os protestos de teólogos e moralistas dos Séculos XV e XVI, de um FRANCISCO DE VITÓRIO, 1480-1546, seguido por SUAREZ, 1548-1617.

O primeiro, o verdadeiro fundador de um novo direito internacional, anteviu a comunidade internacional dos Estados independentes, mas limitados pelo direito e pela moral, não aceitou se considerassem donos de toda a Terra o Imperador ou o Papa, negando que este tivesse dado aos espanhóis título 
para o domínio do Novo Mundo, mas apenas para a propaganda da fé, vendo, pois, na Bula Inter Coetera eficácia só espiritual.

Condenou a guerra de conquista, dizendo textualmente "Imperii amplificatio non est justa causa belli"; reconheceu a soberania dos indígenas da América sobre suas terras, não distinguindo, juridicamente, cristãos e infiéis; proclamou o direito da livre comunicação ; construiu o direito "intergentes" fora da base privado-individualista do direito romano.

Note-se como ele responde ao argumento dos conquistadores espanhóis, fundados em princípios do direito romano, das Institutas, De Rerum Divisione, N. Ferae Bestiae, da propriedade das coisas desertas e vacantes pelo primeiro ocupante: "Tal Título. en si mismo no puede fundar la posesión de los españoles, del mismo modo que no podria fundar la de los bárbaros en el territorio español, si ellos hubiesen descubierto a nosotros". Note-se, ademais, que eles baseavam o direito de ocupação em texto das Institutas sobre a posse de animais bravios, "Ferae bestiae", reconhecida pela sua captura em qualquer lugar onde ocorresse. Era evidentemente absurdo equiparar à "Ferae bestiae" seres humanos e povos, e alguns grandemente civilizados, como as nações indígenas do México e do Peru. .

4. Infelizmente os dois grandes juristas de então não acompanharam VitóRIA e SUAREZ. AlBERICo GENTILE, 1552-1608 , recorria ao direito romano, imperialista, e ao uso dos Estados nos costumes e praxes seguidos, aproximando-se de MAQUIAVEL, para dar juridicidade às condenáveis práticas criadas pelos Estados em suas relações nos Séculos XV e XVI. E HUGo Grocio, 1583-1645, evitando de um lado a teologia e doutro a política, abstraindo das idéias e dos fatos de seu tempo, "como os matemáticos consideram as figuras", em busca das regras admitidas pela vontade de todos ou da maioria dos povos, dirige-se incessantemente aos autores e obras da antigüidade, em particular ao direito romano, em busca de uma opinião universal, e chega assim a aceitar, por exemplo, a conquista e a escravidão.

Enfim, ao "jus naturalismo" puro de um PUFENDoRFF, 1632-1694, ou de um WOLFF, 1679-1754, opôs-se o voluntarismo predominante de um ZoucH, 1590-1660, de um RACHEL, 1628-1691, e de um BYNKERSHOECK, 1673-1743, que vai vencer, no futuro, com MOSER, 1701-1785 e VON MARTENS, 1756-1821, e influenciar de modo relevante o "eclético" VATTEL, 1714-1767, que era "nettement individualiste", fazendo predominar 
"l'interét de l'Etat isolé sur celui de la communauté internationale".

5. E, assim, um direito internacional aristocrático-individualista, do equilíbrio político de um pequeno grupo de Estados poderosos, passando de Portugal e Espanha para Holanda, Espanha e França, prossegue vitorioso nos Tratados de Westphalia, 1648 e de Utrecht, 1713, na Pentarquia, no Congresso de Viena de 1815, se consolida na prática dos governos, e se desenvolve na Europa, dos Séculos XVIII e XIX, com as teorias filosóficas da soberania absoluta do Estado do Século XVIII e do seu endeusamento com HEGEL, no Século XIX.

Os ideais humanitários da Revolução Francesa foram vozes perdidas no deserto e imediatamente abafadas na mesma França e pela própria Revolução. Mas esse próprio direito internacional tão precário, ainda é considerado uma regalia dos Estados europeus. Representa, de fato, um aristocrático direito das potências da Europa, que só o aplicavam entre si, adotando "outras" regras para os povos da América Latina, da África ou da Ásia, não "cristãos" ou não "civilizados" numa distinção já inadmitida, qual se viu, por Francisco VitóRIA. E o clássico HeFTer quem afirma, textualmente: "À l'égard des Etats non chrétiens, comme de ceux qui n'on pas été admis d' une manière regulière dans le sein de la famille européenne, l'application du même droit (droit international de l'Europe) est tout à fait libre et fondée sur une reciprocité purement conventionelle. Les relations avec eux se forment d'aprés les exigences de la politique et de la morale". Mas PRADIER FodERÉ referindo-se a tal direito, "réel, tel qu'il existe à notre époque", a propósito da sua substituição fora da Europa pelas exigências "de la politique et de la morale", acrescenta: "de la politique surtout et presque exclusivement".

Ficavam, assim, as potências da Europa com as mãos livres para continuar a colonização dos outros continentes, para excluí-los do direito internacional, arrogando-se o direito de selecionar os Estados que poderiam ter acesso a tal direito, a fazer parte da comunidade das nações européias e cristãs.

Falava-se, apenas, em direito das gentes, europeu, no Século XVIII com MaBLY, Droit Public de l'Europe...., e de MARTENS, Droit des Gens Moderne de l'Europe, e internacionalistas, em especial germânicos, do Século XIX, KLUBER, SCHMALZ, HEFTER, VON NEUMANN, VON HOLTZENDORFF, QUARITSCHT, RESCH, intitularam seus livros: Das europaischen volkrecht, Direito das Nações, Direito Internacional da Europa. 
A Rússia só entrou nesse direito europeu no Século XVIII. Note-se, ainda, o que diz MARCEL Sibert: “à la suite de la guerre de Crimée, l'article 7 du Traité de 30 Mars 1866 déclara la Sublime Porte admise a participer aux avantages du droit public et du concert européen".

6. O "clássico", aristocrático, direito internacional exacerbou-se no Século XIX, através de uma nova e bárbara concentração colonizadora, na África, afinal com uma Conferência de Berlim para a consumação da partilha daquele continente entre as grandes potências européias. Ali os africanos não tiveram representantes e foi surpresa escandalosa pedir o delegado dos Estados Unidos, KASSON, "o consentimento voluntário dos indígenas para a validade da ocupação".

Completou-se mesmo a ação colonizadora com uma partilha da Ásia, entre a Rússia, o Império Britânico e a França.. 2

7 Grandioso impacto renovador receberia o D.I. no Século XIX e princípios do Século XX, vindo do continente americano, com o seu D.I. regional, comunitário, orgânico e, pois, com alto espírito universalista.

Em verdade os Estados da América Latina no Século XIX e nos princípios do Século XX sentiram, através de violências, espoliações, enfim, das maiores injustiças, o tratamento que as potências européias, dizendo-se "cristâs" e "civilizadas" lhes dispensavam sob as exigências da política e da moral (H. Valladão. Democr. e Socializ. do D.I., cit). No Brasil Pimenta Bueno e, depois Clóvis Bevilaqua, tiveram ocasião de verberar, os atentados das grandes potências contra os direitos do cristianíssimo e civilizado Império do Brasil.

o primeiro impacto que as potências européias e o seu direito internacional sofreram se verificou com a proclamação pelos Estados Unidos, através do Presidente Monroe, em mensagem de 2 de dezembro de 1823, ao Congresso, de que:

2. Em uma autorizada crítica do D.I. europeu, C. H. Alexandrowicz, cursos na Academie de la Haye (Recueil, 100/207 e 123/123, 1968) mostrou que a Europa se estabeleceu, no Século XIX como uma espécie de "found club of Family of Nations", com sua "eurocentric law", apresentada pela sua "positivist school of thought" E reclama contra o rebaixamento da Ásia, em especial dos Estados das Indias Orientais, por ela então feito quando antes, nos Séculos XVI e XVII, acreditava diplomatas e concluía tratados (assim Portugal, Espanha, Holanda, França) com Estados das mesmas Indias, citando o Tratado de Poona, 1769, entre o Vice-Rei de Coa, em nome da Coroa de Portugal, e Peshova, Chefe do Estado de Marathra, que veio a ser aplicado em 1960 pela. Corte de Haia no litígio entre Portugal e a fndia acerca dos "enclaves" de Diu e Nassar. 
"O continente americano dada a condição livre e independente que tinha assumido e mantinha não podia ser mais considerado como sujeito à colonização futura de nenhum Estado Europeu". Desta e de outras declarações da mensagem concluía-se, qual mostrou, com segurança, ALEJANDRo ALVAREZ, pela adoção, em oposição aos correntes no direito internacional europeu, destes novos princípios: o direito adquirido dos Estados americanos à independência, o direito de não sofrerem intervenção em sua vida e forma de governo, a proibição de colonização no Novo Mundo. A autonomia e a solidariedade do continente americano já tinham sido formuladas no Tratado de Madri, de 1750, entre Espanha e Portugal, pelo brasileiro AleXANDRE DE GUSMÃo, que RodRIgo OCTAVIo chamou: precursor de MONRoE. A origem latino-americana, próxima, da proclamação dos Estados Unidos decorria de anteriores manifestações de Bolivar, ARTigas, O'Higgins, SAN MARTin, e de notas do colombiano MANUEL TORRES ao Presidente Monroe e ao seu Secretário de Estado, Adams, todas no sentido de combater a ação das Potências da Europa visando reconquista, intervenção e colonização H. VALLADÃo, Democr. e Socializ. do D.I., cit.).

Começam, então, as jovens nações latino-americanas a organizar suas relações internacionais, afirmando princípios de um novo direito internacional, profundamente democrático e humano, proclamando e adotando regras que se tornariam universais, integrando o verdadeiro direito internacional da humanidade. Da luta de gigantes, de dois grandes internacionalistas da América, do chileno ALEJANDRo ALVAREZ, com a tese, Le Droit International Américain, 1910, e do brasileiro Manuel álvaro de Souza Sá Vianna, com a antítese, De la Non Existence d'un Droit International Americain, 1912, resultou a grandiosa síntese de que há princípios do direito internacional, hoje básicos, fundlamentais, que se originaram ou que se consolidaram por meio de declarações, tratados, convenções e práticas dos Estados Latino Americanos e assim se incorporam ao direito internacional (H. VALLADÃo, PAZ, Direito Técnica, p. 262).

Representou, assim, o direito internacional americano a larga cooperação das Américas para o progresso e o devido aperfeiçoamento do direito das gentes. Era a repercussão no plano internacional, dos princípios democráticos, da supremacia da Constituição e da Lei, da liberdade e da igualdade, dos direitos e garantias do homem, das Revoluções Americana e Francesa, que, repudiados na Europa com a reação vitoriosa 
da Santa Aliança, tinham sido efetivados nas Constituições e Códigos da América Latina.

Era a reação lógica contra o despótico direito internacional europeu, "des grandes puissances", decorrente dos princípios absolutistas das monarquias do velho mundo.

Já em 1824 o Brasil, segundo escreveu Rodrigo Octavio, propunha aos Estados Unidos, sob a ação imediata da mensagem de Monroe, uma aliança no sentido de assegurar que "para o futuro, na América, a política européia não prevaleceria sobre a política americana". No primeirc Congresso Internacional Americano, do Panamá, de 1826, se firma a idéia da solidariedade continental, na aliança para defesa da soberania, independência, e integridade territorial de todas as nações da América, e se esboçam as primeiras idéias da resolução amigável por transação das divergências, de submissão destas à assembléia geral, de não se declarar guerra sem uma prévia exposição dos fatos à decisão conciliadora da mesma assembléia. No Congresso seguinte, de Lima, 1847/8, vão se desenvolvendo os grandes princípios da manutenção da integridade territorial, da não intervenção, da substituição da guerra pelas soluções pacíficas, negociações diplomáticas diretas, bons ofícios, arbitragem, decisão do Congresso de Plenipotenciários, da extradição até do nacional, salvo para os crimes políticos, da abolição do corso. E continuaram nos Tratados Continentais de Santiago e de Washington, de 1956, que avançam no equiparar aos nacionais os naturais de qualquer dos Estados contratantes, e no Congresso de Lima, de 1864, onde se aperfeiçoam os princípios anteriores, em especial com a proscrição da guerra e a instituição de arbitramento inapelável.

De outra parte o Brasil defendia e sustentava nos Tratados com a Argentina e o Uruguai e depois com estes e o Paraguai, após guerra em que foi obrigado a tomar parte, que a vitória militar não conferia direitos a ficar com qualquer porção, mínima que fosse, de território de propriedade do vencido ${ }^{3}$.

$\mathrm{E}$ os dois supremos princípios verdadeiramente constitucionais, de um autêntico direito internacional, o da proscrição

3. Esse nobre padrão jurídico do Brasil e o seu amor pela solução pacífica dos conflitos internacionais explicaram sua convocação ao alto cenário internacional logo que se tratou de progredir no assunto, e foi, assim, em 1871, um dos cinco árbitros no grande, decisivo e célebre julgamento de 14 de setembro de 1872, que consagrou o Juízo arbitral da célebre questão do "Alabama" entre a Inglaterra e os Estados Unidos a veio a ser o superárbitro nas reclamações de nacionais da França, Itália, Alemanha e Bélgica contra o Chile, em conseqüência da Guerra do Pacífico, 1884/5. 
da guerra, substituída pelo arbitramento obrigatório, e o da condenação da conquista, desconhecidos no direito internacional europeu, foram referidos no Brasil pelo Imperador Dom Pedro II, 1888, e incluídos na Constituição da República, 1891: "Artigo 88. Os Estados Unidos do Brasil, em caso algum, se empenharão em guerra de conquista, direta ou indiretamente, por si ou em aliança com outra nação" e "Artigo 34. Compete privativamente ao Congresso Nacional: 11. Autorizar o governo a declarar guerra, se não tiver lugar ou malograr-se o recurso do arbitramento, e a fazer a paz", mantidos nas posteriores até o presente (H. VALladÃo, Democr. e Socializ. do D.I., cit.).

Mas no direito internacional, vigente da Europa, de então, não se acreditava, ainda, nos grandes efeitos da arbitragem, combatia-se mesmo sua adoção e eficácia e era corrente o direito de conquista, aceitava-se para a aquisição de territórios, "La Conquête debellatio", qual se pode ver das lições do autorizado internacionalista F. DE MARTENS, expressando sentir geral no Velho Mundo, BLUNTsCHLI, CARNAZzA AMARI, PIEDELIEVRE.

No entanto já surgem, em nosso continente, obras de direito internacional que versam problemas internacionais americanos; assim, de autores sul-americanos, SEIJAS, RAFAEL, I., El Derecho Internacional hispano-americano, publico $e$ privado, 5 volumes, 1884/1886, e AlCORTA, A., Curso de Derecho Internacional, Buenos Aires, 1886. $\mathrm{E}$ da própria Europa, PRADIER FoDERÉ que já havia durante vários anos exercido larga atividade universitária e cultural em Lima, no Peru, iniciava edição do seu notável Traité de Droit International Public Européen et Américain, o $10^{\circ}$ volume de 1886 e os outros seguindo-se em número de 6, até 1906 . No título e na Introdução (n. XV) acentuava que consideraria o direito internacional "au point de vue des principes, des besoins et des voeux de la démocratie", revelada aí a influência que sofrera do largo convívio anterior latino-americano. $\mathrm{Na}$ obra brasileira, Principios de Direito Internacional, v. I, 1901, p. 22/23, LAFAYETTE RODRIGUES PEREIRA sustentava que o direito internacional "pode, pois, corretamente, denominar-se "Direito Público Externo Europeu-Americano", e combatendo o afastamento dos Estados do Norte da África e da Ásia, "da comunhão do Direito das Nações Cultas" porque "não professam o Cristianismo" mostrava que "as nações infiéis têm as mesmas qualidades fundamentais, a mesma natureza e os mesmos fins das cristãs", citando a declaração de FrANCisco DE VITóRIA, 
que a diferença de religião não é causa justa para a guerra, e concluindo que viessem elas "a fazer parte da Sociedade dos Estados Europeus e Americanos".

De outra parte, convocada em 1888, reuniu-se em $1889 / 1890$, em Washington, chamadas todas as nações americanas, a 1. ${ }^{\text {a }}$ Conferência Internacional Americana, declarando em Resoluções propostas pelo Brasil e pela Argentina, de 18 de abril de 1890, que os Estados americanos: "adotam a arbitragem como princípio do Direito Internacional Americano", "obrigatório", só excetuando, restritamente, "questões sobre sua independência", e, ainda mais, "que o princípio da conquista fica eliminado do direito público americano durante - tempo do tratado de arbitragem", sendo "nulas as cessões de território verificadas sob ameaça de guerra ou pressão da força armada", e "ineficaz a renúncia de recorrer à arbitragem para discutir a validade de tais cessões" (vd. H. VALladão, Democr. e Socializ. do D.I. cit.). Note-se que na $1 .^{a}$ Confer., 1889 , se esboçara o ideal de codificação do D.I., concretizado na 2. ${ }^{a}$ Confer. Internac. Amer., México, 1902, aprovado na $3 .^{a}$ Confer., Rio, 1906, em Convenção, ratificada, criando a Comissão Internacional de Juristas Americanos destinada a preparar um Código de Dir. Internac. Público e outro de Dir. Internac. Priv. cuja obra veremos a seguir.

Tais princípios, na evolução natural de idéias novíssimas, com recuos e avanços, tinham surgido das nações latino-americanas dos princípios aos meados do Século XIX e vieram assim e afinal a serem admitidos, sem quaisquer restrições nas Américas nos termos atuais: da repulsa do uso da força e da obrigatoriedade da resolução de toda e qualquer questão entre os Estados por meios pacíficos, pela conciliação, arbitragem ou pela Justiça Internacional (a Corte de Justiça Centro-Americana de 1907 é a 1. ${ }^{a}$ Corte Internacional), da proscrição da conquista territorial com o não reconhecimento de nenhuma aquisição feita pela violência pois "a vitória não dá direitos". Outros princípios, de origem americana, vão se consolidando: assim o da condenação da intervenção de um Estado nos negócios internos ou externos de outro da ilicitude da cobrança compulsória das obrigações pecuniárias (doutrina Drago).

$\mathrm{E}$ os Congressos e depois as Conferências internacionais de todos os Estados Americanos, em pé de igualdade, iniciavam uma organização solidária internacional americana, com seu órgåo, a União Pan-Americana, sem exclusão de qualquer Estado americano e sua doutrina, o Pan-americanismo diplomático, com vivência da $1 .^{\mathrm{a}}, 1889$ às seguintes, do México, 
1902, Rio, 1906, Buenos Aires, 1911, Santiago, 1925, Havana, 1928, Montevidéu, 1933 e seguintes.

As novas bases verdadeiramente democráticas do direito internacional estavam postas nas Américas e teriam que se incorporar ao direito universal.

8. Havia de ser na 2. ${ }^{a}$ Conferência Internacional da Paz de Haia, de 1907, o esperado encontro entre o antigo, aristocrático e individualista direito internacional europeu, dos Séculos XV a XIX e princípios do XX, e o novo, democrático e humano direito internacional americano, dos Séculos XIX e $\mathrm{XX}^{4}$.

Reuniam-se pela primeira vez os Estados independentes do mundo, e nesta assembléia universal de Nações, os povos da América, em especial os da América Latina (19 Estados), apresentaram aos do Velho Mundo, em verdade aos da Europa, os novíssimos princípios democráticos que haviam instituído na comunidade internacional do hemisfério ocidental.

Assim foi com a arbitragem obrigatória, sendo qualificado de "certamente ousado" o projeto da República Dominicana que a estabelecia em todas as questões, sem qualquer exceção, substituído, afinal, por outro, mais tímido, para as questões de ordem jurídica que não comprometessem os interesses vitais, a honra e a independência dos Estados, projeto este que apesar de aceito por todos os Estados das Américas, e vários da Europa, tendo a frente Portugal e Grã-Bretanha, caiu por falta de unanimidade, em face de oposição chefiada pela Alemanha. Chocou tão profundamente a opinião pública mundial esse insucesso da Conferência, que foi mister, na Ata Final, incluir uma declaração proclamando que unanimemente se reconhecia o princípio da arbitragem obrigatória, e que para certas questões, em especial as referentes à interpretação e aplicação das convenções, seria admitido sem restrições.

Sobre a exclusão do emprego da força armada para cobrança de dívidas, o princípio latino-americano foi acolhido, em forma restrita, em caso de recusa à oferta de arbitragem (proposta Palter), determinando tal limitação sérias reservas o delegado do Brasil, RUI BARBoSA, levantou na Conferência de muitos estados da América Central e do Sul. Na ocasião,

4. Na 1. Conferência da Paz de Haia, em 1899, não teve maior repercussão a existência das nações latino-americanas, convidada que fora apenas uma delas, o México. 
"une question grave, la plus importante de toutes pour la paix du monde et pour la civilization du globe" e que se fosse então resolvida, "ce serait la bénediction de cette conference", a da abolição do direito de conquista, "le fleau de la conquête, toujours a l'horizon des peuples comme un signe de misère et de désolation", abolição que era da tradição do direito constitucional brasileiro, propondo, porém, apenas, a limitação daquele direito ao caso de recusa de arbitramento oferecido pelo conquistador, proposta que apesar de sua timidez foi considerada "memorável" e a mais radical já "apresentada", e não foi, sequer, considerada. embora refletisse o sentimento das nações pacifistas.

Outro grandioso princípio por ele defendido, o da igualdade dos Estados soberanos, a propósito de Projeto de Corte Judiciária dando oito lugares, privativa e permanentemente, às oito grandes potências, teve apoio incondicional dos Estados latino-americanos, determinando a rejeição do referido Projeto.

A conclusão a tirar dos trabalhos da $2 .^{a}$ Conferência da Paz de Haia é que iria surgir dali um novo direito internacional, universal e democrático, sob a influência de novos princípios, de origem americana, que, expostos, discutidos, defendidos, aceitos em parte, desvendaram ao Velho Mundo os progressos revolucionários do direito das gentes realizados no Novo Mundo. 